\title{
Novel T Cell Epitope Designing from PPRV HN Protein for Peptide based Subunit Vaccine: An Immune Informatics Approach
}

\author{
Aditya Agrawal $^{1 *}$, Rohini Gupta ${ }^{2}$, Anil Gattani ${ }^{1}$, Shailesh Kumar Patel $^{3}$, \\ Mahvash Hira Khan ${ }^{1}$ and Praveen Singh ${ }^{1}$ \\ ${ }^{1}$ Division of Animal Biochemistry, IVRI, Izatnagar, Bareilly, U.P. India \\ ${ }^{2}$ Division of Medicine, IIVER, Rohtak, Haryana, India \\ ${ }^{3}$ Division of Pathology, IVRI, Izatnagar, Bareilly, U.P. INDIA, India \\ *Corresponding author
}

\section{A B S T R A C T}

Peste-des-petits Ruminants (PPR) is a disease of small ruminants especially goat and its control and eradication till 2030 wants an extensive research to develop a

\section{Keywords}

PPR virus, $\mathrm{HN}$ protein, T cell epitope, MHC

\section{Article Info}

Accepted:

20 February 2020

Available Online:

10 March 2020 potent vaccine. The role of surface HN protein in the attachment of the virus to cellular receptors makes it an appropriate target to develop a theranostics against the virus. In this study, cytotoxic T cells epitopes that will bind to MHC class I alleles were predicted out using bioinformatic tools. Ten immunogenic peptides were predicted using IEDB web server based on their binding with cow (BoLA) alleles. Among these predicted peptides, five immunogenic epitopes i.e. ${ }^{429}$ SVFGPLIPHL $^{438}, \quad{ }^{86}$ HQTKDVLTPL $^{95}, \quad{ }^{261}$ RDLGLGPPVF $^{270}$, ${ }^{432}$ GPLIPHLSGM $^{441}$ and ${ }^{555}$ VRLNFKGNPL $^{564}$ were selected on the basis of their high percentile score. Predicted three dimensional (3D) models of the PPRV HN protein and SLAM receptor were built and used to dock the immunogenic epitopes. It was used to predict the docked site in the structure. Furthermore, the involvement of these predicted epitopes in experiments may lead to creation of novel potent vaccine and diagnostic tools against the PPR.

\section{Introduction}

Peste des petits ruminant (PPR) is an acute, highly contagious and morbid viral disease of goat and other small ruminants caused by PPR virus which comes under genus morbillivirus, affecting livestock of more than 70 countries (Kumar et al., 2014; Prajapati et al., 2019). The occurrence of the PPR virus mainly occurs during winters (Singh et al., 2014) and their seroprevalence were reported throughout the country (Balamurugan et al., 2014a; Hota et al., 2018; Pal et al., 2014; Saritha et al., 2014). The economic impact by the PPR was already reported and its control may help the poor farmers in their growth (Staal et al., 2009; Kamel and El-Sayed, 2019). The surface protein haemagglutinin 
neuraminidase (HN) of PPR virus involves in the virus attachment and induces acquired immunity in the host cell ( $\mathrm{Yu}$ et al., 2017). The inhibition of HN resulting in restriction of its attachment may lead to control the disease. Using conserved epitopes to develop a potent vaccine is a novel concept that applied in control of various harmful diseases (Gershoni et al., 2007; Iurescia et al., 2012; Abu haraz et al., 2017; Tahir et al., 2019). Therefore, prediction and analysis of the novel epitopes of PPRV $\mathrm{HN}$ protein is a crucial step to develop a peptide subunit based vaccine, antiviral peptides and diagnostic tools. In this study, cytotoxic $\mathrm{T}$ cells epitopes against PPRV HN protein were predicted out using immunoinformatics tools that may bind to MHC class I alleles and their docking has been performed to find their predicted docking site. The main motive of this study is to design a novel antiviral peptides or multiepitopic vaccine that restricts the virus attachment and helps in control and eradication of the PPR.

\section{Materials and Methods}

\section{Retrieval of amino acid sequences}

The amino acid sequences of hemagglutininneuraminidase of PPRV Sungri-96 strain (GenBank accession number: GQ452016.1) and SLAM receptor precursor of Ovis aries (NCBI Reference Sequence: NP_001035378.1) was retrieved from NCBI database (http://www.ncbi.nlm.nih.gov/ protein/).

\section{Predictions of $\mathrm{T}$ cell epitopes}

Immune Epitope Database (IEDB) prediction tools (http://tools.iedb.org/mhci/) were emphasized to predict cytotoxic T lymphocyte (CTL) epitopes of PPRV HN protein using retrieved sequence (609 AA residues) that may interact with $\mathrm{MHC}$ (major histocompatibility complex) class I alleles (Lundegaard et al., 2008). Eight different cow alleles i.e. BoLA-T2a, BoLA-T5, BoLA-T2b, BoLA-D18.4, BoLA-T2c, BoLA-JSP.1, BoLA-T7 and BoLA-HD6 were used for analysis using netmhcpan_el4.0 method to predict the binding affinity. The length of amino acids was fixed to 10 and the cut off percentile rank was set in the range of 1-4 during the prediction of $\mathrm{T}$ cell epitopes.

\section{Three dimensional (3D) modeling and docking}

Due to non-availability of the crystal structure of PPRV HN protein in PDB format, the predicted 3D model of the PPRV HN protein from the retrieved sequence was built using SWISS-MODEL online server (https://swissmodel.expasy.org/interactive)

(Biasini et al., 2014). Similarly predicted 3D model of the SLAM receptor was built from retrieved sequence (338 amino acids) in intensive mode using Phyre 2.0 web server (http://www.sbg.bio.ic.ac.uk/phyre2/html/pag e.cgi?id=index) (Kelley et al., 2015). Furthermore, docking has been performed between the predicted peptide sequences of the PPRV HN protein and predicted 3D model of SLAM receptor using HPEPDOCK online web server (http://huanglab.phys.hust.edu.cn/hpepdock/) (Zhou et al., 2018).

\section{Results and Discussion}

\section{Predicted cytotoxic T cell epitopes}

In this study, using MHC-I binding prediction method of IEDB web server, the surface immunogenic epitopes of PPRV HN protein were predicted out. A total of 10 fixed length T-cell epitopes that will interact with various cow (BoLA) alleles were selected along with their percentile rank and position (table 1). Out of ten predicted CTL immunogenic 
epitopes, three epitopes viz. ${ }^{429}$ SVFGPLIPHL $^{438},{ }^{86} \mathrm{HQTKDVLTPL}^{95}$ and ${ }^{555}$ VRLNFKGNPL $^{564}$ were interacted with four BoLA alleles. The four epitopes i.e. ${ }^{243}$ VWRSDARDPS $^{252},{ }^{261}$ RDLGLGPPVF $^{270}$ ${ }^{432}$ GPLIPHLSGM $^{441}, \quad{ }^{474}$ NRAEVMPHIL $^{483}$ and three epitopes i.e. ${ }^{59}$ RLHRATVGTL ${ }^{68}$, ${ }^{196}$ AHFSELTLTL ${ }^{205}$ and ${ }^{520}$ MDLRYITATY $^{529}$ were predicted to interact with three and two BoLA alleles respectively. The peptide epitope ${ }^{429}$ SVFGPLIPHL ${ }^{438}$ and ${ }^{555}$ VRLNFKGNPL ${ }^{564}$ obtained the highest percentile rank of 3.8 and 3.3 respectively in comparison to other predicted $\mathrm{T}$ cell epitopes indicating the most probable potent immunogenic $\mathrm{T}$ cell epitopes of PPRV HN protein.

\section{D modeling of PPRV HN protein and SLAM receptor}

The 3D model of PPRV HN protein created by Swiss model revealed the sequence identity of $39.48 \%$ with measles virus (MV) haemagglutinin $(\mathrm{H})$ protein using template 2zb5.1 (Crystal structure of the measles virus hemagglutinin) (Fig.1A). Furthermore, the final model posses an overall coverage of 0.76 and sequence similarity of 0.40 . Then the QMEAN, $C \beta$, solvation and torsion values of the model were recorded as $-4.89,-1.06,-1.84$ and -3.97 respectively under global quality estimation. In addition, the 3D model of SLAM receptor built in intensive mode using Phyre 2.0 revealed $72 \%$ of amino acids modeled with greater than $90 \%$ confidence using template c2druA (crystal structure and binding properties of the $\mathrm{cd} 2$ and $\operatorname{cd} 244$ (2b4)2 binding protein, cd48) (Fig.1B).

\section{Docking of predicted $\mathbf{T}$ cell epitopes on SLAM receptor}

From the list of predicted immunogenic epitopes, five epitopes i.e. ${ }^{429}$ SVFGPLIPHL $^{438}, \quad{ }^{86}$ HQTKDVLTPL $^{95}$,
${ }^{261}$ RDLGLGPPVF $^{270}, \quad{ }^{432}$ GPLIPHLSGM $^{441}$ and ${ }^{555}$ VRLNFKGNPL ${ }^{564}$ were selected on the basis of their higher percentile rank and docked as ligands with 3D model of the SLAM receptor on the HPEPDOCK web server. After docking, the binding site model of the epitope with highest docking score was chosen. Among the docked peptides, the epitope ${ }^{429}$ SVFGPLIPHL ${ }^{438}$ docked more efficiently and compactly with the docking score of -183.89 . The rest of the epitopes i.e. ${ }^{86}$ HQTKDVLTPL $^{95}, \quad{ }^{261}$ RDLGLGPPVF $^{270}$, ${ }^{432}$ GPLIPHLSGM $^{441}$ and ${ }^{555}$ VRLNFKGNPL $^{564}$ were also docked successfully and obtained a docking score of $161.267,-170.062,-174.309$ and -170.882 respectively (Fig.2).

\section{Discussion}

Due to huge economic consequences and morbidity rate, the control and global eradication of the PPR has been initiated. The most effective approach to control and eradicate the PPR is vaccination of livestock. To develop a potent multiepitopic vaccine, accurate prediction of the surface epitopes is a crucial step. Most of the morbilliviruses infection leads to the immunosuppression which may be protected by cell-mediated and humoral immune response against specific surface protein (Naik et al., 1997). In the study, the cytotoxic $\mathrm{T}$ cell epitopes were predicted out using cow (BoLA) alleles in order to bind with MHC-I alleles and their docking with SLAM receptor was performed using bioinformatics tools. Earlier studies reported the use of various animal and human alleles to predict the immunogenic $\mathrm{T}$ cell epitopes against multiple diseases using immunoinformatics (Patronov and Doytchinova, 2013; Liu et al., 2017; Idris et al., 2018; Abd Albagi et al., 2017; PrabdialSing et al., 2012; Ahmad et al., 2019; Prasasty et al., 2019). 
Table.1

\begin{tabular}{|c|c|c|c|c|c|}
\hline S.No. & Peptide & Position & Length & Alleles & $\begin{array}{c}\text { Percentile } \\
\text { Rank }\end{array}$ \\
\hline 1. & SVFGPLIPHL & $429-438$ & 10 & $\begin{array}{c}\text { BoLA-T2a } \\
\text { BoLA-T2b } \\
\text { BoLA-T5 } \\
\text { BoLA-D18.4 }\end{array}$ & $\begin{array}{l}2.3 \\
2.0 \\
3.8 \\
2.6\end{array}$ \\
\hline 2. & RLHRATVGTL & $59-68$ & 10 & $\begin{array}{l}\text { BoLA-T2c } \\
\text { BoLA-T7 }\end{array}$ & $\begin{array}{l}2.3 \\
2.0\end{array}$ \\
\hline 3. & HQTKDVLTPL & $86-95$ & 10 & $\begin{array}{c}\text { BoLA-T2c } \\
\text { BoLA-T2b } \\
\text { BoLA-T7 } \\
\text { BoLA-T5 }\end{array}$ & $\begin{array}{l}2.3 \\
2.0 \\
2.7 \\
2.0\end{array}$ \\
\hline 4. & AHFSELTLTL & $196-205$ & 10 & $\begin{array}{l}\text { BoLA-HD6 } \\
\text { BoLA-JSP. } 1\end{array}$ & $\begin{array}{l}1.4 \\
1.1\end{array}$ \\
\hline 5. & VWRSDARDPS & $243-252$ & 10 & $\begin{array}{l}\text { BoLA-T2c } \\
\text { BoLA-T2b } \\
\text { BoLA-T2a }\end{array}$ & $\begin{array}{l}1.7 \\
1.8 \\
2.3\end{array}$ \\
\hline 6. & RDLGLGPPVF & $261-270$ & 10 & $\begin{array}{c}\text { BoLA-HD6 } \\
\text { BoLA-T5 } \\
\text { BoLA-D18.4 }\end{array}$ & $\begin{array}{l}2.3 \\
2.4 \\
2.7\end{array}$ \\
\hline 7. & GPLIPHLSGM & $432-441$ & 10 & $\begin{array}{c}\text { BoLA-T2c } \\
\text { BoLA-HD6 } \\
\text { BoLA-T7 }\end{array}$ & $\begin{array}{l}2.8 \\
2.7 \\
2.9\end{array}$ \\
\hline 8. & NRAEVMPHIL & $474-483$ & 10 & $\begin{array}{c}\text { BoLA-D18.4 } \\
\text { BoLA-T5 } \\
\text { BoLA-T2b }\end{array}$ & $\begin{array}{l}1.5 \\
2.3 \\
1.4\end{array}$ \\
\hline 9. & MDLRYITATY & $520-529$ & 10 & $\begin{array}{c}\text { BoLA-D18.4 } \\
\text { BoLA-T5 }\end{array}$ & $\begin{array}{l}1.9 \\
1.7\end{array}$ \\
\hline 10. & VRLNFKGNPL & $555-564$ & 10 & $\begin{array}{c}\text { BoLA-HD6 } \\
\text { BoLA-T5 } \\
\text { BoLA-T7 } \\
\text { BoLA-D18.4 }\end{array}$ & $\begin{array}{l}2.0 \\
2.9 \\
3.3 \\
2.7\end{array}$ \\
\hline
\end{tabular}

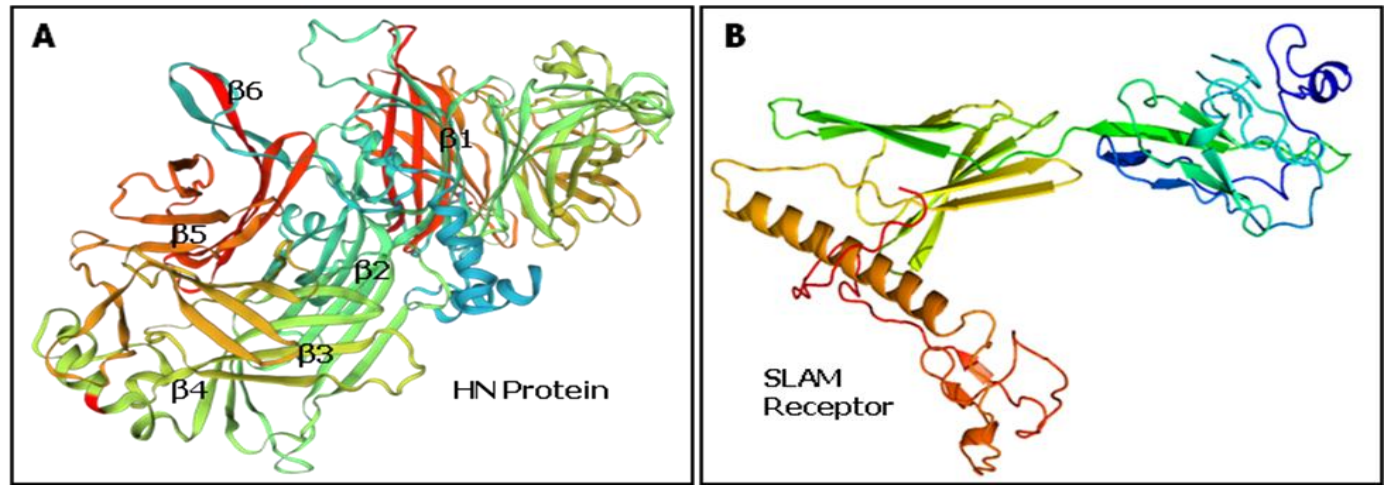

Figure.1 Depiction of predicted 3D structure

A) PPR virus HN protein by SWISS MODEL software. Predicted structure consists of six antiparallel beta propeller sheets. B) SLAM receptor by Phyre 2.0 software 


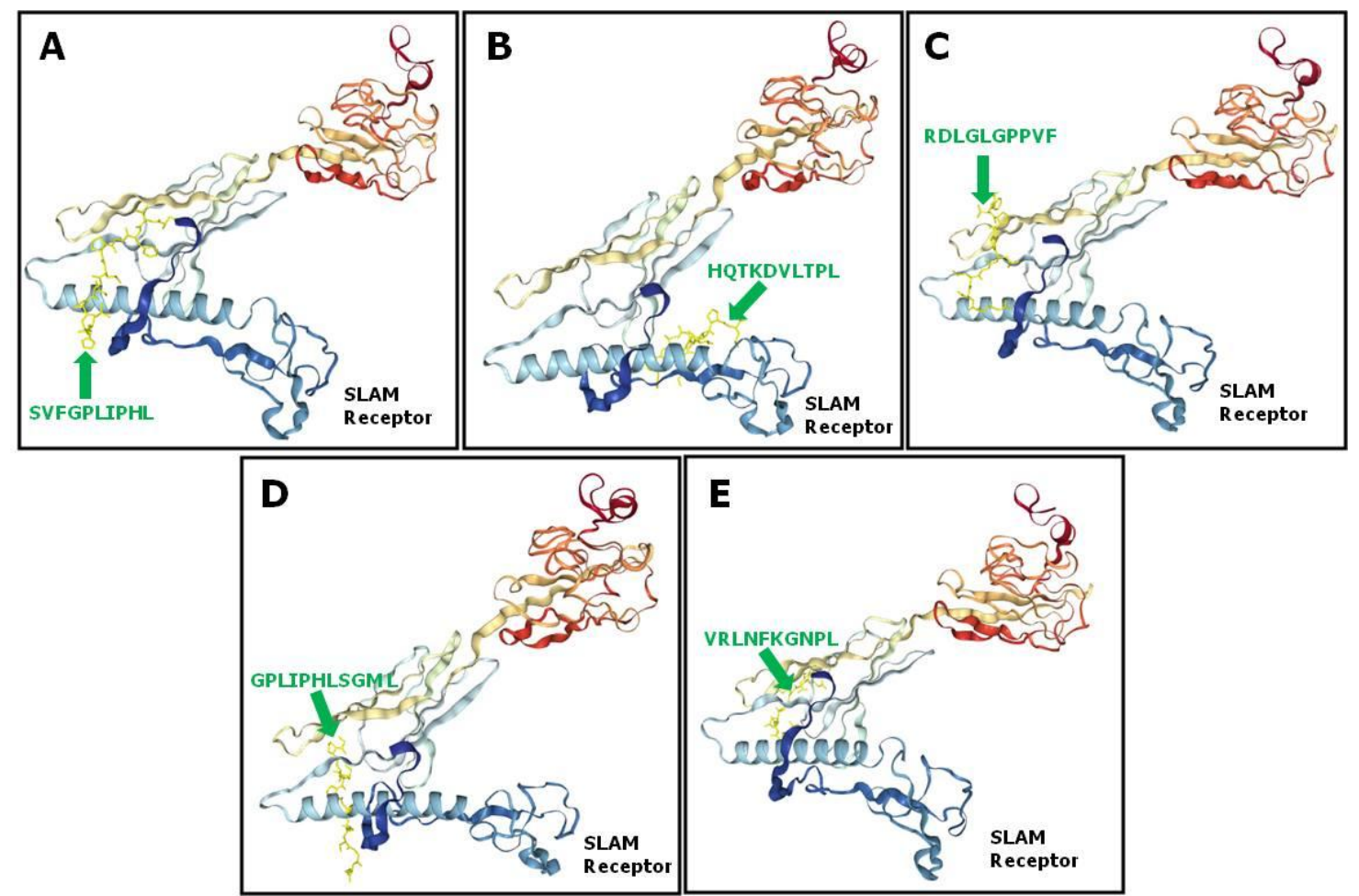

Figure.2 Representation of the docking position of predicted peptide epitopes of PPRV HN protein on 3D model of SLAM receptor using HPEPDOCK server

Previously, a docking between the MHC 1 and $\mathrm{T}$ cell peptide of chimeric protein of colorectal cancer using HPEPDOCK server was performed and results indicate a successful interaction with a docking score of -209.839 (Hassan et al., 2020). Furthermore, the $\mathrm{H}$ protein of the $\mathrm{MV}$ is highly homologous to the PPR HN protein and the interaction of the head domain of $\mathrm{MV} \mathrm{H}$ protein with the SLAM receptor was reported earlier (Hashiguchi et al., 2011). As per reports, due to absence of adequate bioinformatics tools, only $10 \%$ of the predicted $\mathrm{T}$ cell epitopes were found immunogenic (Zhong et al., 2003).

These findings indicated that the predicted epitopes might be able to bind and restrict the virus attachment and may work as potent antiviral agents. However, in-vitro and in-vivo experiments must be needed to validate and confirm the immunogenic epitopes that potentially binds to the MHC molecules.
In this study, ten immunogenic peptides were predicted as $\mathrm{T}$ cell epitopes using IEDB web tool. Out of these predicted peptides, five potent epitopes i.e. ${ }^{429} \mathrm{SVFGPLIPHL}^{438}$, ${ }^{86}$ HQTKDVLTPL $^{95}, \quad{ }^{261}$ RDLGLGPPVF $^{270}$, ${ }^{432}$ GPLIPHLSGM $^{441}$ and ${ }^{555}$ VRLNFKGNPL ${ }^{564}$ were identified on the basis of their high percentile score and their probable binding affinity with multiple BoLA alleles. 3D model of the PPRV HN protein and SLAM receptor was built and docking of the predicted immunogenic peptides was done using these predicted models.

Furthermore, experimentation using these predicted epitopes will lead to designing of specific theranostics tools which helps in the control and global eradication of the PPR.

\section{Acknowledgments}

The authors would like to thanks Director and staff members of the Indian Veterinary 
Research Institute, Izatnagar Bareilly U.P. for their support and cooperation.

\section{References}

Abd Albagi, S. O., Ahmed, O. H., Gumaa, M. A., Abd elrahman, K. A., Abu Haraz, A. H., and Hassan, M. A. (2017). Immunoinformaticspeptide driven vaccine and in silico modeling for Duvenhage rabies virus glycoprotein G. Journal of Clinical \& Cellular Immunology. 8(4): 517.

Ahmad, B., Ashfaq, U. A., Rahman, M. U., Masoud, M. S. and Yousaf, M. Z. (2019). Conserved B and T cell epitopes prediction of ebola virus glycoprotein for vaccine development: An immunoinformatics approach. Microbial pathogenesis. 132: 243-253.

Balamurugan, V., Krishnamoorthy, P., Raju, D. S., Rajak, K. K., Bhanuprakash, V., Pandey, A. B., Gajendragad, M. R., Prabhudas, K. and Rahman, H. (2014). Prevalence of Peste-des-petits-ruminant virus antibodies in cattle, buffaloes, sheep and goats in India. Virusdisease, 25(1), 85-90.

Biasini, M., Bienert, S., Waterhouse, A., Arnold, K., Studer, G., Schmidt, T., Kiefer, F., Gallo Cassarino, T., Bertoni, M., Bordoli, L. and Schwede, T. (2014). SWISS-MODEL: modelling protein tertiary and quaternary structure using evolutionary information. Nucleic Acids Research.42(Web Server issue): W252-W258.

Gershoni, J. M., Roitburd-Berman, A., Siman-Tov, D. D., Tarnovitski Freund, N. and Weiss, Y. (2007). Epitope mapping: the first step in developing epitope-based vaccines. BioDrugs. 21(3): 145-156.

Hamdi, A., Khoubieb A. A., Ibrahim, M. H., Hussein W. H., Mohammed, Badawi M. M. and Hassan M. A. (2017). Multi epitope peptide vaccine prediction against Sudan ebola virus using immuno-informatics approaches. Advanced Techniques in Biology \& Medicine. 5(1): 203.

Hashiguchi, T., Ose, T., Kubota, M., Maita, N., Kamishikiryo, J. Maenaka, K. and Yanagi, Y. (2011). Structure of the measles virus hemagglutinin bound to its cellular receptor SLAM. Nature Structural and Molecular Biology. 18: 135-141.

Hassan, D., Chalbatani, G.M., Gharagouzloo, E., Miri, S. R., Memari, F., Rasoolzadeh, R., Zinatizadeh, M. R., Zarandi, P. K. and Marmari, V. (2020). In silico Analysis, Molecular Docking, Molecular Dynamic, Cloning, Expression and Purification of Chimeric Protein in Colorectal Cancer Treatment. Drug Design, Development and Therapy. 14: 309.

Hota, A., Biswal, S., Sahoo, N., Rout, M., Chaudhary, D., Pandey, A. and Muthuchelvan, D. (2018). Seroprevalence of PPR among Sheep and Goats of Different Agroclimatic Zones of Odisha. International Journal of Livestock Research. 8(4): 296-302.

Idris, S. T., Salih, S., Basheir, M., Elhadi, A., Kamel, S., Khoubieb, A. A., Ahmed, H. and Mohamed, A. H. (2018). In silico prediction of peptide based vaccine against fowlpox virus (FPV). Immunome Research. 14(2): 154.

Iurescia, S., Fioretti, D., Fazio, V. M. and Rinaldi, M. (2012). Epitopedriven DNA vaccine design employing immunoinformatics against B-cell lymphoma: a biotech's challenge. Biotechnology Advances. (1): 372-383.

Kamel, M. and El-Sayed, Amr. (2019). Toward peste des petits virus (PPRV) eradication: Diagnostic approaches, novel vaccines, and control strategies. 
Virus Research. 274: 197774.

Kelley, L. A., Mezulis, S., Yates, C. M., Wass, M. N., Sternberg, M. J. 2015. The Phyre2 web portal for protein modeling, prediction and analysis. Nature protocols. 10(6), 845-858.

Kumar, N., Maherchandani, S., Kashyap, S. K., Singh, S. V., Sharma, S., Chaubey, K. K. and Ly, H. (2014). Peste des petits ruminants virus infection of small ruminants: A comprehensive review. Viruses. 6(6): 2287-2327.

Liu, Y. F., Lin, C. Y. and Hong, H. M. (2017). In silico design, synthesis and potency of an epitope-based vaccine against foot and mouth disease virus. International Journal of Pharmacology. 13(2): 122-133.

Lundegaard, C., Lund, O. and Nielsen, M. (2008). Accurate approximation method for prediction of class I MHC affinities for peptides of length 8,10 and 11 using prediction tools trained on 9mers. Bioinformatics. 24(11): 1397-1398.

Naik, S., Renukaradhya, G. J., Rajasekhar, M. and Shaila, M. S. (1997). Immunogenic and protective properties of haemagglutinin protein $(\mathrm{H})$ of rinderpest virus expressed by a recombinant baculovirus. Vaccine. 15(6-7): 603-607.

Pal, S., Isore, D. P., Mukhopadhayay, S. K., Ganguly, S. and Das, M. (2014). Seroprevalence and Incidence of PPR among population of small ruminants in West Bengal, India. International journal of pharmaceutical research and bio-science. 3(3): 396-401.

Patronov, A. and Doytchinova, I. (2013). Tcell epitope vaccine design by immunoinformatics. Open Biology. 3(1): 120-139.

Prabdial-Sing, N., Puren, A. J. and Bowyer, S. M. (2012). Sequencebased in silico analysis of well studied hepatitis $\mathrm{C}$ virus epitopes and their variants in other genotypes (particularly genotype 5a) against South African human leukocyte antigen backgrounds. BMC Immunology. 13(1): 67.

Prajapati, M., Alfred, N., Dou, Y., Yin, X., Prajapati, R., Li, Y. and Zhang, Z. (2019). Host Cellular Receptors for the Peste des Petits Ruminant Virus. Viruses. 11(8): 729.

Prasasty, V. D., Grazzolie, K., Rosmalena, R., Yazid, F., Ivan, F. X. and Sinaga, E. (2019). Peptide-Based Subunit Vaccine Design of $\mathrm{T}$ - and B-Cells MultiEpitopes against Zika Virus Using Immunoinformatics

Approaches. Microorganisms. 7(8): 226.

Saritha, G., Shobhamani, B. and Sreedevi, B. (2014). Sero-Prevalence of Peste des petites ruminants in Pastoral Small ruminants with special reference to age and agro-climatic zone. Animal Science Reporter. 8(3): 103-107.

Singh, B., Bardhan, D., Verma, M. R., Prasad, S. and Sinha, D. K. (2014). Estimation of economic losses due to Peste de Petits Ruminants in small ruminants in India. Veterinary World. 7(4): 194-199.

Staal, S., Poole, J., Baltenweck, I., Mwacharo, J., Notenbaert, A., Randolph, T., Thorpe, W., Nzuma, J., Herrero, M. (2009). Strategic investment in livestock development as a vehicle for rural livelihoods; International Livestock Research Institute: Nairobi, Kenya, pp. 1-78.

Tahir Ul Qamar, M., Saleem, S., Ashfaq, U. A., Bari, A., Anwar, F. and Alqahtani, S. (2019). Epitope-based peptide vaccine design and target site depiction against Middle East Respiratory Syndrome Coronavirus: an immuneinformatics study. Journal of Translational Medicine. 17(1): 362.

Yu, R., Zhu, R., Gao, W., Zhang, M., Dong, S., Chen, B., Yu, L., Xie, C., Jiang, F. 
and $\mathrm{Li}, \mathrm{Z}$. (2017). Fine mapping and conservation analysis of linear B-cell epitopes of peste des petits ruminants virus hemagglutinin protein. Veterinary Microbiology. 208: 110-117.

Zhong, W., Reche, P. A., Lai, C. C., Reinhold, B. and Reinherz, E. L. (2003). Genome-wide characterization of a viral cytotoxic $\mathrm{T}$ lymphocyte epitope repertoire. The Journal of Biological Chemistry. 278(46): 4513545144.

Zhou, P., Jin, B., Li, H. and Huang, S. Y. (2018). HPEPDOCK: a web server for blind peptide-protein docking based on a hierarchical algorithm. Nucleic Acids Research. 46(W1): W443-W450.

\section{How to cite this article:}

Aditya Agrawal, Rohini Gupta, Anil Gattani, Shailesh Kumar Patel, Mahvash Hira Khan and Praveen Singh. 2020. Novel T Cell Epitope Designing from PPRV HN Protein for Peptide based Subunit Vaccine: An Immune Informatics Approach. Int.J.Curr.Microbiol.App.Sci. 9(03): 2432-2439. doi: https://doi.org/10.20546/ijcmas.2020.903.278 